\title{
Results of endovascular repair of the thoracic aorta with the Talent Thoracic stent graft: The Talent Thoracic Retrospective Registry
}

Rossella Fattori, MD, ${ }^{a}$ Christoph A. Nienaber, MD, ${ }^{b}$ Hervé Rousseau, MD, ${ }^{c}$ Jean-Paul Beregi, MD, ${ }^{d}$ Robin Heijmen, MD, Martin Grabenwöger, MD, ${ }^{\mathrm{f}}$ Philippe Piquet, MD, ${ }^{\mathrm{g}}$ Luigi Lovato, MD, ${ }^{\mathrm{a}}$ Chaouki Dabbech, MD, ${ }^{\mathrm{c}}$ Stephan Kische, MD, Virginia Gaxotte, MD, ${ }^{\mathrm{d}}$ Marc Schepens, MD, ${ }^{\mathrm{e}}$ Marek Ehrlich, MD, ${ }^{\prime}$ and Jean-Michelle Bartoli, MD ${ }^{\mathrm{h}}$

Cardiovascular Radiology, University Hospital S. Orsola, Bologna, Italy ${ }^{\mathrm{a}}$; Division of Cardiology, University Hospital Rostock, Rostock, Germany ${ }^{\mathrm{b}}$; Department of Radiology, Centre Hospitalier Universitaire, Hôpital de Rangueil, Toulouse, Francec; Radiologie Vasculaire, Hôpital Cariologique CHRU de Lille, Lille, France ${ }^{\text {; }}$ Department of Cardiothoracic Surgery, St. Antonius Hospital, Nieuwegein, The Netherlands ; Department of Cardio-Thoracic Surgery, University of Vienna, Vienna, Austria $^{f}$; Department of Vascular Surgery, Centre Hospitalier Universitaire, Hôpital Sainte Marguerite, Marseille, Frances; and Department of Interventional Radiology, Centre Hospitalier Universitaire, Hôpital de la Timone, Marseille, France. ${ }^{\mathrm{h}}$

This is a company registry study of the Medtronic Talent Thoracic stent graft. Authors Rossella Fattori, Christoph A. Nienaber, Hervé Rousseau, Jean-Paul Beregi, and Robin Heijmen each report receiving consulting and/or lecture fees from Medtronic.

Received for publication Dec 26, 2005; revisions received Feb 21, 2006; accepted for publication March 15, 2006

Address for reprints: Rossella Fattori, Department of Radiology-Cardiovascular Unit (pad 21), University Hospital S.Orsola, Via Massarenti 9, 40128 Bologna, Italy (E-mail: rossella.fattori@unibo.it).

J Thorac Cardiovasc Surg 2006;132:332-9

$0022-5223 / \$ 32.00$

Copyright $(\odot) 2006$ by The American Association for Thoracic Surgery

doi:10.1016/j.jtcvs.2006.03.055
Background: Endovascular treatment of thoracic aortic diseases demonstrated low perioperative morbidity and mortality when compared with conventional open repair. Long-term effectiveness of this minimally invasive technique remains to be proven. The Talent Thoracic Retrospective Registry was designed to evaluate the impact of this therapy on patients treated in 7 major European referral centers over an 8-year period.

Methods: Data from 457 consecutive patients (113 emergency and 344 elective cases) who underwent endovascular thoracic aortic repair with the Medtronic Talent Thoracic stent graft (Medtronic/AVE, Santa Rosa, Calif) were collected. Follow-up analysis (24 \pm 19.4 months, range 1-85.1 months) was based on clinical and imaging findings, including all adverse events. To ensure consistency of data interpretation and event reporting, one physician reviewed all adverse events and deaths for the whole cohort of patients. In the case of discrepancies, the treating physicians were queried.

Findings: Among 422 patients who survived the interventional procedure (inhospital mortality 5\%, 23 patients), mortality during follow-up was 8.5\% (36 patients), and in 11 of them the death was related to the aortic disease. Persistent endoleak was reported at imaging follow-up in 64 cases: 44 were primary $(9.6 \%)$ and 21 occurred during follow-up (4.9\%). Seven patients with persistent endoleak had aortic rupture during follow-up, at a variable time from 40 days to 35 months, and all subsequently died. A minor incidence of migration of the stent graft (7 cases), graft fabric alteration ( 2 cases), and modular disconnection (3 cases) was observed at imaging. Kaplan-Meier overall survival estimate at 1 year was $90.97 \%$, at 3 years was $85.36 \%$, and at 5 years was $77.49 \%$. At the same intervals, freedom from a second procedure (either open conversion or endovascular) was $92.45 \%$, $81.3 \%$, and $70.0 \%$, respectively.

Conclusion: Endovascular treatment for thoracic aortic disease with the Talent stent graft is associated with low early morbidity and mortality rates also for patients who are at high risk and treated on an emergency basis. Follow-up data indicate a substantial durability of the procedure with a high freedom from related death and secondary interventions.

$\mathrm{T}$ he natural history of degenerative thoracic aortic disease is progressive and may lead to dilation, dissection, and rupture. Aggressive medical treatment and careful imaging follow-up contributed to improve survival of patients with thoracic aortic diseases. However, medical therapy alone can only delay, but not avoid, aneurysm expansion and rupture: reported 5-year mortality is $16 \%$ for aneurysms smaller than $6 \mathrm{~cm}$ in diameter and $31 \%$ for aneurysms larger than $6 \mathrm{~cm}$ 


\author{
Abbreviations and Acronyms \\ ASA $=$ American Society of Anesthesiologists \\ $\mathrm{CI}=$ confidence interval \\ $\mathrm{CT}=$ computed tomography \\ MRI = magnetic resonance imaging \\ $\mathrm{OR}=$ odds ratio \\ TTR $=$ Talent Thoracic Retrospective Registry
}

in diameter. ${ }^{1-3}$ Therefore, preventive surgical resection has long been considered the only treatment strategy, although associated with significant mortality and morbidity. ${ }^{4-9}$

The advent of endovascular techniques revolutionized the management of thoracic aortic disease, enabling lowinvasive repair even in high-risk patients unfit for open surgery. Compared with open surgery, stent-graft treatment is associated with decreased perioperative mortality rates and fewer complications, even in older patients with significant comorbidities. ${ }^{10-23}$ However, data on midterm and long-term follow-up are limited. The Talent Thoracic Retrospective Registry (TTR) was designed to collect outcome data from patients who underwent endoluminal treatment with the Medtronic Talent thoracic stent graft (Medtronic/ AVE, Santa Rosa, Calif) in 7 European referral centers. Data collection was focused on clinical and imaging follow-up with particular reference to mortality and long-term complications.

\section{Methods \\ Enrolment}

The entire cohort study consisted of 457 consecutive patients who underwent endovascular thoracic aortic repair with the Talent Thoracic stent graft between November 1996 and March 2004. Seven European referral centers (Bologna, Toulouse, Rostock, Lille, Vienna, Nieuwegein, and Marseille) provided data from patients treated consecutively, with a minimum of 1-month follow-up. The ethical committee of each institute approved the study. Baseline demographic and clinical characteristics are listed in Table 1, including information on comorbidities, American Society of Anesthesiologists (ASA) class, previous cardiac or aortic surgery, aneurysm/dissection anatomy, and operative and postoperative courses. Follow-up analysis was formed on clinical and imaging findings until the last visit date, including all adverse events. Postoperative imaging findings were focused to any evidence of expansion of aneurysm size or graft-related problems, such as kinking, migration, modular disconnection, or integrity of the graft fabric. Data were collected on case report forms and entered in two separate databases by a data collection specialist and by the lead author (R.F.; Maastricht, The Netherlands, and Bologna, Italy). Case report forms were all reviewed by the lead author and checked for inconsistencies. In case of discrepancies, the participating investigator at each site was queried to ensure appropriate interpretation of events. The two different databases were then compared and errors in data entries were corrected by checking on the specific case report form.
TABLE 1. Demographics and clinical characteristics of patients $(n=457)$

\begin{tabular}{lcr}
\hline & No. & $\%$ \\
\hline Male & 350 & 76.6 \\
Age, y (mean \pm SD) & $59.6 \pm 16$ & \\
ASA class (>III) & 256 & 56 \\
Previous aortic surgery & 103 & 22.5 \\
Previous cardiac surgery & 21 & 4.6 \\
Hypertension & 331 & 72.4 \\
Renal insufficiency & 72 & 15.7 \\
COPD & 102 & 22.3 \\
Diabetes & 48 & 10.5 \\
CVA & 33 & 7.2 \\
Marfan syndrome & 15 & 3.2 \\
Smoking & 110 & 24.1 \\
Aortic disease (total) & & \\
Degenerative aneurysm & 137 & 29.9 \\
Dissection & 180 & 39.4 \\
Posttraumatic aneurysm & 85 & 18.6 \\
Pseudoaneurysm & 14 & 3.1 \\
Penetrating ulcer & 29 & 6.3 \\
Intramural hematoma & 12 & 2.6 \\
Aortic disease (acute) & 113 & 24.7 \\
Degenerative aneurysm & 18 & \\
Dissection & 37 & \\
Posttraumatic aneurysm & 41 & \\
Pseudoaneurysm & 4 & \\
Penetrating ulcer & 8 & \\
Intramural hematoma & 5 & \\
\hline
\end{tabular}

$S D$, Standard deviation; ASA, American Society of Anesthesiologists; $C O P D$, chronic obstructive pulmonary disease; CVA, cerebral vascular accident.

\section{Patient Characteristics}

The registry comprises 350 male and 107 female patients with a mean age of 59.6 years, ranging from 19 to 91 years (Table 1). The spectrum of thoracic aortic diseases comprised 180 (39.4\%) thoracic aortic dissections, $137(29.9 \%)$ atherosclerotic aneurysms, 14 (3\%) pseudoaneurysms, $29(6.3 \%)$ penetrating ulcers, $12(2.6 \%)$ intramural hematomas, and $85(18 \%)$ posttraumatic aneurysms (Table 1). Two hundred fifty-six (56\%) patients were classified as ASA class III/IV/V. Previous cardiac or aortic surgery was reported on $21(4.6 \%)$ and $103(22.5 \%)$ patients, respectively, while $5(1.1 \%)$ patients had already received endovascular therapy for abdominal aortic aneurysm. Mean aortic diameter for the aortic dissection and atherosclerotic aneurysms was $60.1 \pm 16.7$ (range: 26-136 mm) (Table 2).

\section{Imaging Evaluation}

Before treatment all patients were examined by at least one tomographic imaging modality, such as computed tomography (CT) and magnetic resonance imaging (MRI), in addition to angiography or transesophageal echocardiography. Information on maximum aneurysm diameter or on dissection size, proximal and distal anatomic extension, and distance from the left subclavian artery were recorded. CT scan alone (33\%) or in association with angiography 
TABLE 2. Procedural details and early results (457 patients)

\begin{tabular}{|c|c|c|}
\hline & No. & $\%$ \\
\hline General anesthesia & 453 & 99.1 \\
\hline Maximum diameter (dissection and & 307 & \\
\hline $\begin{array}{l}\text { atherosclerotic aneurysms), } \\
\mathrm{mm} \text { (mean } \pm \mathrm{SD})\end{array}$ & $60.1 \pm 16.7$ & \\
\hline Length of covered aorta, mm (mean \pm SD) & $131.5 \pm 44.1$ & \\
\hline \multicolumn{3}{|l|}{ Stent-graft segment used } \\
\hline One & 312 & 68.3 \\
\hline Two & 94 & 20.6 \\
\hline Three & 35 & 7.6 \\
\hline More than three & 5 & 1.1 \\
\hline $\begin{array}{l}\text { Descending aorta proximal (distance from } \\
\text { the } \mathrm{LSA}<1 \mathrm{~cm} \text { ) }\end{array}$ & 124 & 27.1 \\
\hline Occlusion of the LSA & 54 & 11.8 \\
\hline With previous revascularization & 22 & \\
\hline Without previous revascularization & 32 & \\
\hline In-hospital mortality & 23 & 5.1 \\
\hline Emergency & $9 / 113$ & 7.9 \\
\hline Elective & $14 / 344$ & 4.1 \\
\hline \multicolumn{3}{|l|}{ Procedure technical failure } \\
\hline $\begin{array}{l}\text { Impossibility of stent insertion or } \\
\text { deployment }\end{array}$ & 10 & 2.2 \\
\hline Conversion to surgery & 10 & 2.2 \\
\hline Persistent endoleak & 44 & 9.6 \\
\hline In-hospital complications & 58 & 12.7 \\
\hline Stroke & 17 & 3.7 \\
\hline Paraplegia & 8 & 1.7 \\
\hline Vascular local & 15 & 3.3 \\
\hline Extension of dissection & 5 & 1.1 \\
\hline Cardiac & 7 & 1.5 \\
\hline Pulmonary & 2 & 0.4 \\
\hline Renal & 4 & 0.8 \\
\hline
\end{tabular}

$S D$, Standard deviation; $L S A$, left subclavian artery.

(22\%) or angiography combined with MRI (15\%) was the most frequently used imaging method. Imaging follow-up was assessed according to the set protocol of each center, generally consisting of 30 days to 6 months and yearly CT or MRI: CT was performed in $85 \%$ and MRI in $21 \%$ of cases. A chest x-ray film was also obtained in $21 \%$ of patients. Information regarding aneurysm expansion or reduction in size, endoleak, aneurysm sac/false lumen thrombosis, and stent-graft material alteration were collected.

\section{Device Description}

The Talent Thoracic stent graft is composed of a Dacron graft material supported by self-expanding nitinol springs. The springs are sewn to the graft material with polyester sutures. The graft material is a sheet of monofilament polyester with a seam joining the edges to create a cylindrical tube. Opposite the seam is the connecting bar, which attaches the most proximal and distal springs. The connecting bar provides columnar strength to the device and facilitates deployment. During implantation, the connecting bar should be oriented to the outer radius for stent-graft conformability and kink resistance. All nitinol components are surface treated to enhance long-term fatigue performance. The
Talent stent graft system has many modular sections that can be used to treat a wide variety of thoracic lesions. The stent graft has three proximal and distal configurations. The proximal configurations are FreeFlo, Bare Spring (22 mm only), and Open Web, which all have a flared geometry. The FreeFlo design (different from the Bare Spring configuration) has a bare spring and a mini-support spring, which improves sealing for sizes 24 to 46 $\mathrm{mm}$. The distal configurations are Bare Spring, Closed Web, and Open Web. The Open Web configuration was designed for use as distal extensions for the Talent stent-graft system.

\section{Interventional Endovascular Procedure}

General anesthesia was used for the endovascular aortic procedure in 453 of 457 patients. One hundred thirteen (27.4\%) patients were treated under emergency conditions and 344 (75.3\%) patients were treated electively. The mean length of covered aorta was 131.5 $\mathrm{mm}$, ranging from 28 to $380 \mathrm{~mm}$ with one stent used in $70 \%$ of cases. The stent graft was positioned in the proximal descending aortic segment in 124 patients (neck length $>1 \mathrm{~cm}$ ). In 54 patients the stent graft was positioned in the distal aortic arch with coverage of the left subclavian artery to extend the proximal landing zone. In $40.7 \%$ of them (22 patients) revascularization of the left subclavian artery was performed before stent-graft treatment.

\section{Statistical Analysis}

Incidence rates of events are reported by giving the number of patients experiencing the event followed by the corresponding percentage. Continuous data are reported by giving the mean \pm standard deviation and/or median and the range of values observed. Where incidence rates (or proportions) were statistically compared between groups, the $\chi^{2}$ test or Fisher exact test was used. Stepwise logistic regression analysis was performed to determine predictors of in-hospital death and in-hospital complications (stroke, paraplegia, extension of dissection, vascular local, renal, cardiac, pulmonary). Noncorrelated variables with $P<.05$ at univariate analyses were included in the multivariate models; model precision was evaluated by the Hosmer-Lemeshow goodnessof-fit statistic. Estimates of times to events and the accompanying curves were generated by the method of Kaplan and Meier. Statistical analyses were carried out with SPSS software package version 13.0 (SPSS, Inc, Chicago, Ill).

\section{Results}

\section{Procedural Technical Failure}

Technical failure, for example, failure to complete an intended stent-graft deployment, occurred in $10(2.2 \%)$ patients owing to inadequate caliber of the femoral or iliac artery (failure of graft insertion, 7 cases) or difficult deployment (3 cases). Immediate conversion to open repair was documented in $3(0.7 \%)$ cases. Perioperative endoleak was visualized at the end of the procedure in 98 patients (Table 3). However, 26 endoleaks sealed spontaneously during follow-up, whereas an adjunctive endovascular treatment with insertion of a graft extension allowed endoleak resolution in 18 . Ten cases of primary endoleak leading to aneurysm expansion were converted to open surgical repair. Therefore, the rate of persistent primary endoleak was $9.6 \%$ 
TABLE 3. Predictors of in-hospital death and in-hospital complications (logistic regression analysis*)

\begin{tabular}{|c|c|c|c|}
\hline & $\begin{array}{l}\text { Univariate } \\
\text { analysis } P\end{array}$ & $\begin{array}{c}\text { Multivariate } \\
\text { analysis } \\
\text { OR (95\% CI) }\end{array}$ & $\boldsymbol{P}$ \\
\hline \multicolumn{4}{|l|}{ In-hospital death } \\
\hline ASA class $(\geq \mathrm{IV})$ & .01 & $3.00(1.20-7.47)$ & .018 \\
\hline Experience (>2000 y) & .09 & & \\
\hline Age ( $\geq 75$ y) & .03 & $2.49(1.02-6.43)$ & .048 \\
\hline Male & .88 & & \\
\hline Patient status (acute) & .11 & & \\
\hline Traumatic aortic injury & .03 & & \\
\hline Aortic aneurysm & .16 & & \\
\hline Dissection & .66 & & \\
\hline $\begin{array}{l}\text { Penetrating ulcer and } \\
\text { haematoma }\end{array}$ & .43 & & \\
\hline Relevant surgical history & .65 & & \\
\hline Marfan & .98 & & \\
\hline Persistent endoleak & .21 & & \\
\hline Occluded subclavian artery & .60 & & \\
\hline Reintervention & .41 & & \\
\hline \multicolumn{4}{|l|}{ In-hospital complications } \\
\hline ASA class $(\geq \mathrm{IV})$ & $<.0001$ & $2.27(1.16-4.44)$ & .016 \\
\hline Experience $(>2000$ y) & .014 & & \\
\hline Age ( $\geq 75$ y) & .007 & & \\
\hline Male & .12 & & \\
\hline Patient status (acute) & $<.0001$ & $2.79(1.48-5.24)$ & .001 \\
\hline Traumatic aortic injury & .05 & $0.32(0.12-0.81)$ & .016 \\
\hline Occluded subclavian artery & .51 & & \\
\hline
\end{tabular}

$O R$, Odds ratio; $C l$, confidence interval; $A S A$, American Society of Anesthesiologists. *Only variables with $P<.05$ at the univariate analysis were entered into the multivariate analysis.

(44 patients). Endoleak type I was the most common $(7.7 \%)$, whereas the incidence of type III $(0.7 \%)$ and type II $(1.5 \%)$ was very low.

\section{In-hospital Mortality}

The length of hospital stay was 12.8 days (range 1-149) with a median of 9 days. Twenty-three patients died, an in-hospital (within 30 days of the procedure or within the same hospitalization as the primary procedure) mortality of $7.9 \%$ for acute and $4 \%$ for elective cases $(P=.16)$. Two of $23(0.4 \%)$ patients died during the endovascular procedure of aortic rupture; both were emergency cases of type B aortic dissection. Multivariate logistic regression analysis showed that age of 75 years or older (odds ratio [OR] 2.49; 95\% confidence interval [CI] 1.02-6.43; $P=.048)$ and ASA class IV or V (OR 3.0; 95\% CI $1.20-7.47 ; P=.018)$ were independent predictors of in-hospital mortality (94.3\% of correct classification, Hosmer-Lemeshow goodness-of-fit $P=.770$ ) (Table 3). Traumatic aortic injury could not be used in this model because there were no in-hospital deaths in the modeled trauma population. Univariate analysis showed that traumatic aortic injury had a statisti-
TABLE 4. Follow-up data (422 patients)

\begin{tabular}{lcc}
\hline & No. & $\%$ \\
\hline Mortality & & \\
$\quad$ Overall & 36 & 8.5 \\
$\quad$ Death related to aneurysm/dissection & 11 & 2.6 \\
Failure of procedure & & \\
$\quad$ Aortic rupture & 7 & 1.6 \\
Conversion to surgery & 3 & 0.7 \\
Persistent secondary endoleak & 21 & 4.9 \\
Stent-graft complications & & \\
Migration & 7 & 1.6 \\
Modular disconnection & 6 & 1.4 \\
Graft integrity not maintained & 2 & 0.4 \\
Aneurysm/false lumen thrombosis & & \\
Total & 305 & 72.3 \\
Partial & 80 & 18.9 \\
Absent & 18 & 4.3 \\
Not reported & 9 & 2.1 \\
Change in aneurysm dimension & & \\
$\quad$ Increase & 72 & 17.1 \\
Decrease & 165 & 39.1 \\
No change & 50 & 11.8 \\
Not reported & 135 & 32 \\
\hline Length of follow-up, months (mean \pm standard deviation & $24 \pm 19.4$, median \\
19.5, range 1-85.1). & & \\
&
\end{tabular}

cally significantly lower risk of in-hospital death than other etiologies $(P=.03)$ (Table 3$)$.

\section{In-hospital Complications}

Major adverse events are listed in Table 2. The most common were cerebral vascular accidents and vascular trauma during the procedure. Multivariate logistic regression analysis showed that acute status (OR 2.8; 95\% CI 1.5-5.2; $P=.001)$ and ASA class IV or V (OR 2.3; 95\% CI 1.2-4.4; $P=.016)$ were independent predictors of in-hospital complications, whereas traumatic aortic injury was significantly associated to lower rate of complications (OR 0.3; 95\% CI $0.1-0.8 ; P=.016)(86.3 \%$ of correct classification, Hosmer-Lemeshow goodness-of-fit $P=.711$ ) (Table 3). Stroke occurred in 17 patients and was significantly associated to occlusion of the left subclavian artery without previous revascularization ( $P=.004$, Fisher exact test). Paraplegia ( 3 patients) and paraparesis (5 patients) occurred in 8 cases (4 degenerative aneurysm and 4 type B dissection) and was significantly associated to length of covered aorta greater than $20 \mathrm{~cm}(P=.001$, Fisher exact text $)$. At follow-up, the spinal ischemic damage was persistent in the 3 cases of paraplegia, whereas paraparesis resolved completely in 4 of 5 patients.

\section{Mortality and Aortic Rupture at Follow-up}

Clinical and imaging mean follow-up was $24 \pm 19.4$ months (Table 4). Ninety-five of 422 patients had more than 


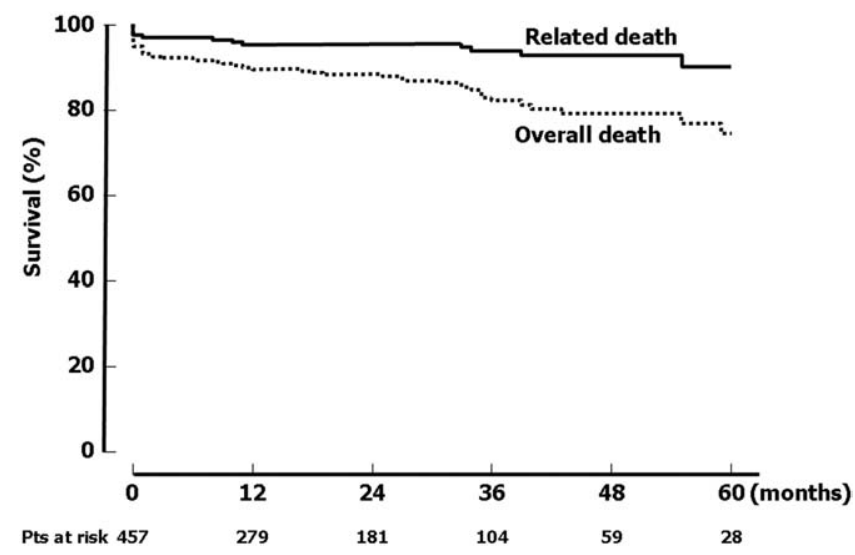

Figure 1. In-hospital and follow-up mortality (overall death and death related to stent-graft procedure).

3 years of clinical and imaging follow-up available, including 23 with over 5 years of follow-up. Late mortality was $8.5 \%$ (36 patients), and in 11 of them death was related to the aorta: 7 cases of aortic rupture at a variable time from 40 days to 35 months, 2 extentions of dissection, and 2 aortoesophageal fistulas (Figure 1). Other cause of death included myocardial infarction, respiratory insufficiency, cerebrovascular accident, and neoplasm. In 5 patients the cause of death was not specified in the case report form. All 7 patients who had an aortic rupture during follow-up subsequently died. Among them, 6 had aortic dissection as primary disease and all 7 patients had type I persistent primary or secondary endoleak, with aneurysm expansion at imaging follow-up (Figure 2).

\section{Secondary Endoleak}

Secondary endoleak (types I and III) was reported in 44 (10.4\%) patients. Endovascular adjunctive treatment al-

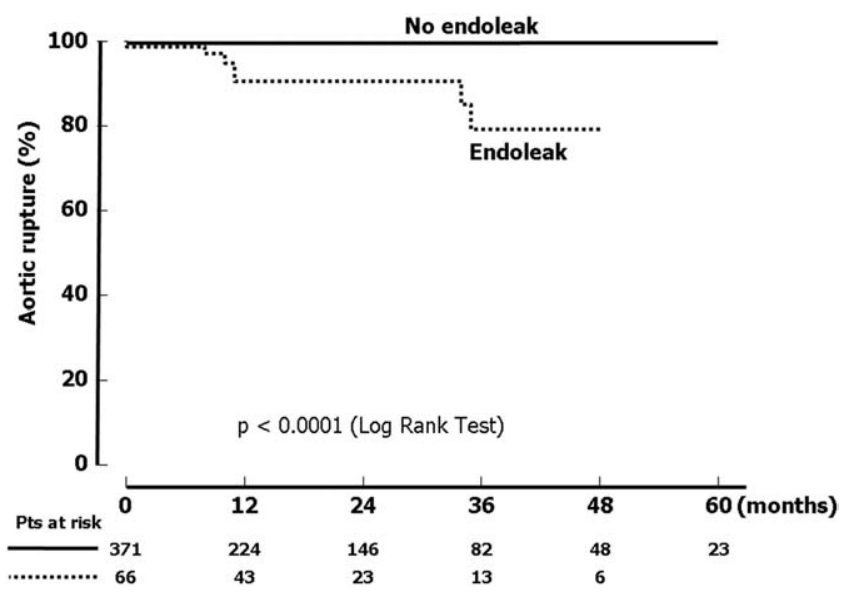

Figure 2. Early and long-term rate of aortic rupture in patients with and without endoleak (log-rank test $P<.0001)$.

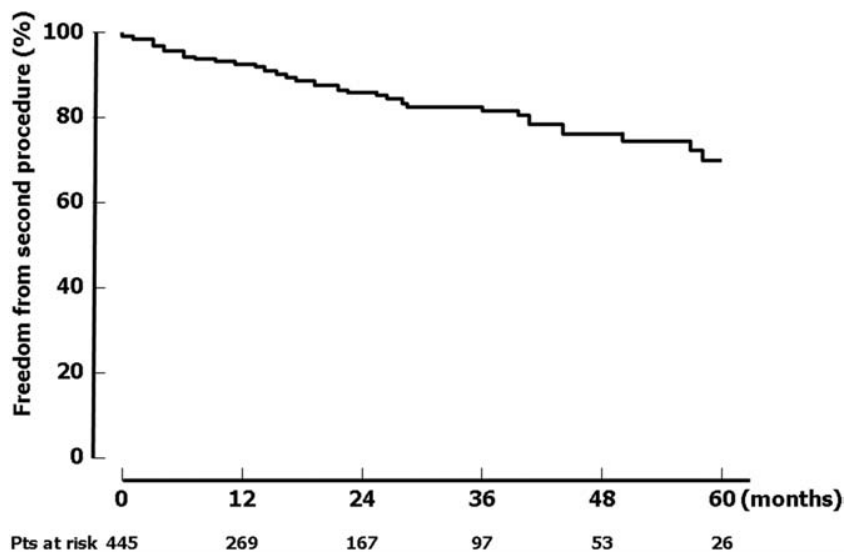

Figure 3. Freedom from second procedure (defined as conversion to surgery or second endovascular treatment) in hospital and during follow-up.

lowed successful sealing in 19 of these patients; one case of spontaneous resolution was recorded, while in 3 additional patients conversion to open repair was necessary (Figure 3). Twenty-one $(4.9 \%)$ patients did not undergo treatment for secondary endoleak.

\section{Stent-graft Complications}

Migration (reported as millimeters of distance of the proximal covered part of the stent graft from the left subclavian artery both at the implant and during follow-up) greater than $5 \mathrm{~mm}$ was observed in 7 patients (median $10 \mathrm{~mm}$, range 5-40 mm). A type I endoleak was present in 2 of them. Disconnection among stent-graft segments was visualized at imaging follow-up in 6 patients, leading to secondary endoleak type III in 4 patients.

Alteration of the graft material was identified in 2 patients. One patient had an aortoesophageal fistula 2 years after successful endovascular treatment of an atherosclerotic aneurysm. On CT scan, a detachment of the distal nitinol frame was noted, facing the esophageal erosion. Another case of proximal detachment of one nitinol frame had no clinical consequences.

\section{Change in Aneurysm Dimension}

The dynamics of aneurysm dimension are summarized in Table 4. Thirteen of 22 patients with endoleak type I (among patients in which this information was reported), either primary or secondary, showed an increase of the aneurysm sac (medium $9 \mathrm{~mm}$, ranging from 5 to $80 \mathrm{~mm}$ ).

\section{Long-term Survival}

Kaplan-Meier overall survival estimate at 1 year was $90.1 \%$, at 3 years was $84.6 \%$, and at 5 years was $74.1 \%$. Kaplan-Meier estimate for freedom from related death was $96.0 \%$ at 1 year, $93.9 \%$ at 3 years, and $90.2 \%$ at 5 years. At the same 
interval, freedom from a second procedure (either open conversion or endovascular) was $92.4 \%, 81.3 \%$, and $70.0 \%$, respectively (Figure 3 ).

\section{Discussion}

Endovascular treatment of descending thoracic aortic diseases is a recent advance among interventional techniques, receiving increasing attention as a nonsurgical alternative to open repair. More notably than in abdominal aortic aneurysm, in which endovascular techniques compare with a lower risk surgery, stent-graft repair for thoracic aortic diseases is able to offer a therapeutic option even to highrisk patients unfit for open surgery. The feasibility of endovascular treatment in thoracic aortic diseases was first reported by Dake and associates ${ }^{10}$ in 1994, using a homemade nitinol-Dacron stent graft in 103 patients. In 1997, commercially manufactured stent grafts enabled increasing use and growth of technical skill and knowledge in many centers. ${ }^{11-20}$ Experience with endovascular treatment in a wide spectrum of aortic diseases demonstrates the feasibility of this approach even in unstable patients with encouraging early and midterm results. ${ }^{21-23}$ However, long-term follow-up of the first thoracic homemade device is discouraging ${ }^{24}$ and associated with low survival. Accordingly, experience with endovascular treatment of abdominal aortic diseases ${ }^{25,26}$ stimulated the need for long-term outcome data and efficacy of the stent graft in aortic diseases. The present experience has some limitations: Data were retrospectively collected, with no control over the inclusion criteria for the endovascular procedure. The lack of a randomized or concurrent control patient group precluded direct comparison with conventional open surgical repair. In addition, the absence of autopsy confirmation in deceased patients does not allow in all cases exclusion of aortic rupture as a possible cause of death.

Yet, this is the first study on long-term results in a wide cohort of patients (457) over an 8-year period, with more than 3 years of clinical and imaging follow-up available in 95 patients. Early results are comparable with other reported case series: in-hospital mortality was 5\%, comprising 113 patients treated under emergency condition. An advantage of endovascular repair in acute aortic syndrome is its potential to reduce blood $\operatorname{loss}^{27,28}$ with respect to open surgery, in which back-bleeding from branch arteries and anastomotic sites or from iatrogenic venous injuries could precipitate shock and neurologic consequences. Most perioperative complications in emergency endovascular cases of this study arose from preexisting medical conditions and were not procedure related. This study showed that in patients with traumatic aortic rupture (85 patients with no mortality), endovascular stent-graft treatment strongly abated the high mortality of conventional open surgical repair. ${ }^{29} \mathrm{In}$ patients with complex multiple trauma, the possibility of low-invasive treatment of the aortic lesion may allow a prompt management of the other associated lesions, with limited impact on trauma destabilization and improved overall survival. The feasibility of endovascular treatment in patients with Marfan syndrome is controversial, because of the particular fragility of the aortic wall. No significant differences in results and outcome emerged from data analysis of the 15 Marfan patients with type B dissection included in this registry. However, no definite results could be drawn from such a limited number of cases.

The present study showed that the most frequent complications in endovascular procedure are stroke $(3.7 \%)$ and vascular lesions at the access site (3.2\%), both probably related to the difficult advancement and manipulation of the sheath, which still has a large outer diameter (22F-27F) and relative inflexibility. New developments of stent-graft material and design might reduce these problems. Among several variables examined, the only significant predictor of stroke was the occlusion of the left subclavian artery without previous revascularization. With regard to intentional left subclavian artery occlusion the available data are conflicting; although recent endovascular reports ${ }^{30}$ suggest a relative safety if some precautions are met, surgical experience with deliberate ligation of the vertebral artery ${ }^{31}$ leads to a $5.4 \%$ rate of ischemic complications.

Spinal cord ischemia with resultant paraplegia is of significant concern with open surgery of descending thoracic aortic aneurysms, ${ }^{32}$ while the endovascular stent graft holds the potential for reducing the risk, avoiding crossclamping, significant blood loss, and severe hypotension. However, experience with endovascular treatment does not allow us to identify the anatomic and clinical characteristics for spinal cord ischemia. Concomitant or previous abdominal aneurysm repair has been reported as a risk factor. ${ }^{26,33}$ In our registry, paraplegia occurred in only 3 patients and it occurred in patients without previous abdominal aortic surgery. Long-segment thoracic aortic exclusion was the most important predictor of spinal ischemia, both for patients with dissection and for those with aneurysm.

Long-term survival is one of the major concerns in patients with severe comorbidities: $56 \%$ of this population had an ASA class of III or more. In this cohort of high-risk patients, Kaplan-Meier curves at 36 months indicate a survival of $84.6 \%$ (Figure 1), with a low incidence of aortarelated deaths $(9 \%)$ and secondary procedures, both surgical and interventional (11\%). Long-term results confirm that endoleak is the most important risk for aortic rupture. All patients with aortic rupture during the follow-up had type I persistent endoleak. According to the literature, ${ }^{34-37}$ type II endoleak, due to reperfusion of the aneurysm sac by intercostal arteries, is relatively uncommon $(0.5 \%$ primary and $0.8 \%$ secondary endoleak) and does not seem to constitute a risk factor for aortic rupture. Migration has not been 
investigated previously in thoracic endografting. ${ }^{38,39}$ Indeed, all previous case series and registries have a maximum of 1-year follow-up or a limited number of patients for longer periods. However, migration seems uncommon in this setting, even several years after implant. In the present series, migration was assessed by reporting differences in the distance of the proximal covered part of the stent graft from the left subclavian artery between the postoperative and subsequent imaging; it occurred in only 7 patients. Although the cases are few, migration was potentially caused by inadequate oversizing or disease progression proximally or distally, resulting in slow enlargement of the landing zones and subsequent loss of fixation. A major concern in endovascular treatment is the durability of the graft material, especially in the case of young patients. Fabric deterioration has been reported with almost all devices in abdominal series and also with thoracic stent grafts. With first-generation endovascular grafts using wire-formed nitinol, electrochemical corrosion leading to stent fracture has been reported, even after a short period of implantation. ${ }^{24}$ Nitinol possesses a high elasticity and very good biocompatibility, and it is known to have good resistance to corrosion, depending on the processing techniques and the quality of the protective titanium oxide surface layer. Improvements in the manufacturing process have led to better quality material and improved the surface finish. Laser cutting, polishing, and heat treatment procedures have enhanced nitinol's corrosion resistance. Our data seem to confirm the durability of the material, with 2 cases in a cohort of 422 patients, some of whom have the stent graft in situ for more than 8 years.

In conclusion, endovascular treatment for thoracic aortic disease with the Talent stent graft carried out at highvolume referral centers is associated with low early morbidity and mortality rates also for patients at high risk and treated on an emergency basis. Follow-up data indicate a substantial durability of the procedure with a high freedom from related death and secondary interventions. Long-term surveillance will be crucial to discover complications unique to thoracic endovascular interventions and to determine which patients are appropriate candidates for stent-graft therapy.

\section{References}

1. Juvonen T, Ergin MA, Galla JD, et al. Prospective study of the natural history of thoracic aortic aneurysms. Ann Thorac Surg. 1997; 63:1533-45.

2. Griepp RE, Ergin MA, Galla JD, et al. Natural history of descending thoracic and thoracoabdominal aneurysms. Ann Thorac Surg. 1999; 67:1927-30.

3. Umana JP, Lai DT, Mitchell RS, et al. Is medical therapy still the optimal treatment strategy for patients with acute type B aortic dissections? J Thorac Cardiovasc Surg. 2002;124:896-910.

4. Crawford ES, Crawford JL, Safi HJ, et al. Thoracoabdominal aortic aneurysms: preoperative and intraoperative factors determining imme- diate and long-term results of operations in 605 patients. $J$ Vasc Surg. 1986;3:389-404.

5. Kouchoukos NT, Dougenis D. Surgery of the thoracic aorta. $N$ Engl J Med. 1997;336:1876-88.

6. Svensson LG, Crawford SE. Statistical analyses of operative results. In: Cardiovascular and vascular disease of the aorta. Philadelphia: Saunders; 1997. pp 432-55.

7. Elefteriades JA, Hartleroad J, Gusberg RJ, et al. Long-term experience with descending aortic dissection: the complication-specific approach Ann Thorac Surg. 1992;53:11-20.

8. Kouchoukos NT, Masetti P, Rokkas CK, Murphy SF, Blackstone EH. Safety and efficacy of hypothermic cardiopulmonary bypass and circulatory arrest for operations on the descending thoracic and thoracoabdominal aorta. Ann Thorac Surg. 2001;73:699-707.

9. Fann JI, Smith JA, Miller DC, et al. Surgical management of aortic dissection during a 30-year period. Circulation. 1995;92(suppl): II113-21.

10. Dake MD, Miller DC, Semba CP, et al. Transluminal placement of endovascular stent-grafts for the treatment of descending thoracic aortic aneurysms. N Engl J Med. 1994;331:1729-34.

11. Dake MD, Kato N, Mitchell RS, et al. Endovascular stent-graft placement for the treatment of acute aortic dissection. $N$ Engl J Med. 1999;340:1546-52.

12. Nienaber CA, Fattori R, Lund G, et al. Nonsurgical reconstruction of thoracic aortic dissection by stent-graft placement. $N$ Engl J Med. 1999;340:1539-45.

13. Sailer J, Peloschek P, Rand T, et al. Endovascular treatment of aortic type B dissection and penetrating ulcer using commercially available stent-grafts. AJR Am J Roentgenol. 2001;177:1365-9.

14. Taylor PR, Gaines PA, McGuinness CL, et al. Thoracic aortic stent grafts-early experience from two centres using commerically available devices. Eur J Vasc Endovasc Surg. 2001;22:70-6.

15. Won JY, Lee DY, Shim WH, et al. Elective endovascular treatment of descending thoracic aortic aneurysms and chronic dissections with stent-grafts. J Vasc Interv Radiol. 2001;12:575-82.

16. Buffolo E, da Fonseca JH, de Souza JA, et al. Revolutionary treatment of aneurysms and dissections of descending aorta: the endovascular approach. Ann Thorac Surg. 2002;74:S1815-7.

17. Cambria RP, Brewster DC, Lauterbach SR, et al. Evolving experience with thoracic aortic stent graft repair. J Vasc Surg. 2002;35:1129-36.

18. Fattori R, Napoli G, Lovato L, et al. Descending thoracic aortic diseases: stent-graft repair. Radiology. 2003;229:176-83.

19. Rousseau H, Soula P, Perreault P, et al. Delayed treatment of traumatic rupture of the thoracic aorta with endoluminal covered stent. Circulation. 1999;99:498-5.

20. Heijmen RM, Deblier IG, Moll FL, et al. Endovascular stent-grafting for descending thoracic aortic aneurysms. Eur J Cardiothorac Surg. 2002;21:5-9.

21. Leurs LJ, Bell R, Degrieck Y, et al. Endovascular treatment of thoracic aortic diseases: combined experience from the EUROSTAR and United Kingdom Thoracic Endograft registries. J Vasc Surg. 2004;40:670-80.

22. Makaroun MS, Dillavou EDa, Kee ST, et al. Endovascular treatment of thoracic aortic aneurysms: results of the phase II multicenter trial of the GORE TAG thoracic endoprosthesis. $J$ Vasc Surg. 2005;41:1-9.

23. White RA, Donayre CE, Walot I, et al. Endovascular exclusion of descending thoracic aortic aneurysms and chronic dissections: initial clinical results with the AneurRX device. J Vasc Surg. 2001;33:927-34.

24. Demers P, Miller DC, Mitchell RS, et al. Mid-term results of endovascular repair of descending thoracic aortic aneurysms with firstgeneration stent grafts. J Thorac Cardiovasc Surg. 2004;127:664-7.

25. Heintz C, Riepe G, Birken L, et al. Corroded nitinol wires in explanted aortic endografts: an important mechanism of failure? $J$ Endovasc Ther. 2001;8:248-53.

26. Alric P, Hinchliffe RJ, Wenham PW, et al. Lessons learned from the long-term follow-up of a first-generation aortic stent-graft. $J$ Vasc Surg. 2003;37:367-73.

27. Grabenwoger M, Fleck T, Czerny M, et al. Endovascular stent graft placement in patients with acute thoracic aortic syndromes. Eur J Cardiothorac Surg. 2003;23:788-93. 
28. Semba CP, Kato N, Kee ST, et al. Acute rupture of the descending thoracic aorta: repair with use of endovascular stent-grafts. J Vasc Interv Radiol. 1997;8:337-42.

29. Pacini D, Angeli E, Fattori R, et al. Traumatic rupture of the thoracic aorta: ten years of delayed management. J Thorac Cardiovasc Surg. 2005;129:880-4.

30. Rehders TC, Petzsch M, Ince H, et al. Intentional occlusion of the left subclavian artery during stent-graft implantation in the thoracic aorta: risk and relevance. J Endovasc Ther. 2004;11:659-66.

31. Steinberg GK, Drake CG, Peerless SJ. Deliberate basilar or vertebral artery occlusion in the treatment of intracranial aneurysms. Immediate results and long-term outcome in 201 patients. J Neurosurg. 1993;79:161-73.

32. Griepp RB, Ergin MA, Galla JD, et al. Looking for the artery of Adamkiewicz: a quest to minimize paraplegia after operations for aneurysms of the descending thoracic and thoracoabdominal aorta. J Thorac Cardiovasc Surg. 1996;112:1202-15.

33. Gravereaux EC, Faries PL, Burks JA, et al. Risk of spinal cord ischemia after endograft repair of thoracic aortic aneurysms. J Vasc Surg. 2001;34:997-1003.
34. White G, Yu W, May J. Endoleak-a proposed new terminology to describe incomplete aneurysm exclusion by an endoluminal graft. J Endovasc Surg. 1996;3:124-5.

35. Fattori R, Caldarera I, Rapezzi C, et al. Primary endoleakage in endovascular treatment of the thoracic aorta: importance of intraoperative transesophageal echocardiography. J Thorac Cardiovasc Surg. 2000;120:490-5.

36. Deaton D, Makaroun M, Fairman RM. Endoleak: predictive value for aneurysm growth at 3 years. Ann Vasc Surg. 2002;16:37-42.

37. Veith FJ, Baum RA, Ohki T, et al. Nature and significance of endoleaks and endotension: summary of opinions expressed at an international conference. J Vasc Surg. 2002;35:1029-35.

38. Holaenbein TJ, Kretschmer G, Thurnher S, et al. Midterm durability of abdominal aortic aneurysm endograft repair: a word of caution. J Vasc Surg. 2001;33:S46-54.

39. Lin JC, Kolvenback R, Wassiliev R, et al. Totally laparoscopic explantation of migrated stent graft after endovascular aneurysm repair: a report of two cases. J Vasc Surg. 2005;41:885-8.

The Journal of Thoracic and Cardiovascular Surgery Conflict of Interest Policy

To assure fairness to authors submitting work for consideration in The Journal of Thoracic and Cardiovascular Surgery, a mechanism exists for managing conflicts of interest. The editor and each of the section editors complete a "Conflict of Interest" form that identifies any and all relationships with commercial and other academic entities. When the editor has a potential conflict because of a relationship with another entity or author, the editor appoints an alternate editor from among the section editors or editorial board members who assumes the entire responsibility for final decisions on the manuscript in question. The editor does not read the reviews that are submitted nor engage in discussing the manuscript prior to the final decision. When the conflict of interest involves a section editor, a "guest section editor" is appointed who fills the role normally played by the conflicted section editor. All members of the editorial board and reviewers are asked to indicate any conflict of interest when they agree to review a manuscript. 